severity of symptoms and increase near term. Close monitoring of fetal wellbeing is essential, although no single test reliably predicts the risk of intrauterine death. Raised serum concentrations of maternal bile acids correlate with the severity of pruritus and risk of fetal distress. ${ }^{10}$ Some obstetricians recommend regular non-stress and contraction stress tests. Delivery should ideally take place around 38 weeks after serial estimations of fetal lung maturity and maternal serum concentrations of total bile acids. Delivery around 36 weeks should be considered for severe intrahepatic cholestasis of pregnancy with jaundice and progressive increases in serum bile acid concentrations if fetal distress is suspected and lung maturity has been confirmed. ${ }^{19}$ The intrapartum fetal heart rate seems an unreliable indicator of fetal distress in intrahepatic cholestasis of pregnancy. ${ }^{9}$ Giving vitamin $K_{1}$ to the baby immediately after birth may help prevent intracranial bleeding.

Recent reports of optimistic fetal outcomes are mostly from experienced referral centres in countries with a high prevalence of the condition. ${ }^{19}$ Maternal and fetal wellbeing are likely to improve with a better understanding of the pathogenetic mechanisms associated with bile acid metabolism, pruritus, and cholestasis. Treatment will be hampered by insufficient data on drug toxicity during late pregnancy in humans.

ELIZABETH ANN FAGAN Visiting professor

University Gastroenterologists,

Rush Presbyterian St Luke's Medical Center,

Chicago, IL 60612,

USA

1 Reyes $\mathrm{H}$, Simon FR. Intrahepatic cholestasis of pregnancy: an estrogen-related disease. Sem Liver Dis 1993;13:289-301.

2 Ahlfeld F.Berichte und Arbeiten aus der geburtshilfich-gynaekologischen Klinik zu Giessen 18811882. Leipzig: Grunow, 1883:148.

3 Eppinger H. Die Leberkrankheiten; allgemeine und spezielle Pathologie und Therapie der Leber. Vienna: Springer-Verlag, 1937.

4 Thorling L. Jaundice in pregnancy. A clinical study. Acta Med Scand 1955;302 (suppl):1-123. 5 Svanborg A. A study of recurrent jaundice in pregnancy. Acta Obstet Gynecol Scand 1954;22:434-44.

6 Jones EA, Bergasa NV. The pruritus of cholestasis and the opioid system. FAMA 1992;268:3359-62.

7 Palma J, Reyes H, Ribalta J, Iglesias J, Gonzalez MC, Hernandez I, et al. Effects of ursodeoxycholic acid in patients with intrahepatic cholestasis of pregnancy. Hepatology 1992;15: 1043-7.

8 Floreani A, Grella V, Gangemi M. Ursodeoxycholic acid in intrahepatic cholestasis of pregnancy. Br f Obstet Gynaecol 1994;101:64-5.

9 Rioseco AJ, Ivankovic MB, Manzur A, Hamed F, Kato SR, Parer JT, et al. Intrahepatic cholestasis of pregnancy: a retrospective case-control study of perinatal outcome. Am 7 Obstet Gynecol 1994;170:890-5.

10 Laatikainen T, Tulenheiko A. Maternal serum bile acid levels and fetal distress in cholestasis of pregnancy. Int $₹$ Gynaecol Obstet 1984;22:91-4.

\title{
Pulmonary emphysema
}

\section{We now understand more about the causes, but effective treatment is some way off}

The treatment of advanced pulmonary emphysema is a serious and depressing problem for respiratory physicians. The patients, mainly smokers or former smokers, suffer from progressive disability and have a reduced life expectancy. Such patients are short of breath on mild exertion and have hyperresonant chests and quiet or absent breath sounds. Destruction of the alveolar walls is a key feature of the disease. ${ }^{1}$

Emphysema can be divided into pathological types according to the distribution of the enlarged air spaces within the acinus (the section of the lung that is supplied by a single terminal bronchiole ${ }^{2}$ ). Two types seem important. In the centriacinar form the enlarged air spaces are in the centre of the acinus close to the terminal bronchioles, and these lesions are usually situated in the upper zones of the lungs. In the panacinar form the whole acinus is affected and lesions may be distributed throughout the lung or concentrated in the lower zones.

The pathogenesis of emphysema remained obscure until Swedish workers discovered the association between panacinar emphysema and a hereditary deficiency of $\alpha_{1}$-proteinase inhibitor. ${ }^{3} \alpha_{1}$-Proteinase inhibitor inhibits proteolytic enzymes, the most important being neutrophil elastase, which can degrade most of the structural proteins of the lung as well as elastin. $\alpha_{1}$-Proteinase inhibitor protects the lung against such proteolytic damage. It is made in the liver and is normally present in the serum in high concentration, but in $\alpha_{1}$-proteinase inhibitor deficiency an error in genetic coding prevents its release from the liver in adequate quantities.

Neutrophils and macrophages can release proteolytic enzymes capable of degrading pulmonary tissue. In smokers and in the presence of infection both cell types increase in number and activity. The main macrophage enzymes are the cysteine proteinases, which are inhibited by the cystatins, and the metalloproteinases, which are inhibited by the specific tissue inhibitors of metalloproteinase. The macrophage enzymes are probably responsible for centriacinar emphysema, in which the lesions seem to be caused by an agent arising in the lumen or the walls of the airways. Neutrophil enzymes are likely to cause the panacinar lesions, the distribution of which suggests that they are caused by a bloodborne agent.

An excess of enzyme or lack of inhibitor is thought to allow structural damage to the lung. This theory receives much additional support from experimental data; lesions similar to those seen in humans with emphysema can be produced in animals by instillation of proteolytic enzymes into their airways. ${ }^{4}$

Nearly all patients with emphysema who have a normal $\alpha_{1}$-proteinase inhibitor phenotype are cigarette smokers, and in patients with $\alpha_{1}$-proteinase inhibitor deficiency smoking greatly increases the severity of the condition. Cigarette smoke could cause emphysema by stimulating neutrophils and macrophages to increase production of proteinases; stimulating them to produce oxidants such as hypochlorous acid, which can inactivate the proteinase inhibitors; suppressing lysyl oxidase, an enzyme required for the synthesis of elastin; or depositing cadmium in the lung, which itself can cause emphysema. Susceptibility to tobacco smoke, however, varies widely as only $10-20 \%$ of smokers develop emphysema. ${ }^{5}$

The theory of proteinase-antiproteinase balance has not gone unchallenged, with suggestions that airflow obstruction in adults is mainly determined in infancy and childhood or even in utero. In animal experiments maternal energy deprivation or hypoxia can reduce fetal pulmonary elastin, which in humans might be presumed to cause emphysema in later life. This question has been addressed by studies in which birth weights recorded 60 to 70 years ago were used as a marker for fetal lung growth. ${ }^{6}$ The mean forced expiratory volume in one second was 
2.57 litres in those with a birth weight greater than $9.5 \mathrm{lb}$ $(4.3 \mathrm{~kg})$ and 2.28 litres in those with a birth weight less than $5.5 \mathrm{lb}(2.5 \mathrm{~kg})$, a difference of statistical though of doubtful clinical significance. The evidence linking childhood respiratory infection with adult airflow obstruction (other than asthma) has been criticised, ${ }^{7}$ though it remains possible that early impairment of lung growth could increase people's susceptibility to cigarette smoke.

Treating emphysema with bronchodilators modestly improves lung function. Even severely affected patients should give up smoking as the rate of deterioration can be slowed appreciably. The prognosis is limited in patients who have ventilatory failure, but a trial of nasal intermittent positive pressure ventilation showed an improvement in patients' clinical condition and reduced mortality. ${ }^{8}$ Lung transplantation has been carried out in many patients with end stage emphysema, including some with $\alpha_{1}$ proteinase inhibitor deficiency. The single lung procedure has good survival rates and is the operation of choice in patients aged over 50.9

Several treatments have been devised to deal with $\alpha_{1}$-proteinase inhibitor deficiency. It seems logical to replace the missing plasma fraction, and $\alpha_{1}$-proteinase inhibitor prepared by fractionation of human plasma or recombinant technology has been given intravenously or by aerosol to patients, with few side effects. ${ }^{10}$ Clearly such treatment could not reverse existing damage, though it might be expected to slow the rate of decline in lung function. No controlled trial of such a product has yet been done, though this seems essential as the treatment is expensive and arduous.

Gene therapy is much in the news, and replacing the defective genetic material is an attractive goal. The techniques hold great interest for the future, ${ }^{11}$ though whether they can fully protect people with $\alpha_{1}$-proteinase inhibitor deficiency remains to be seen.

D C S HUTCHISON Senior lecturer in thoracic medicine

Department of Thoracic Medicine,

King's College School of Medicine and Dentistry, London SE5 9PJ

1 Snider GL, Kleinerman J, Thurlbeck WM, Bengali ZH. The definition of emphysema Am Rev Respir Dis 1985;132:182-5.

2 Lamb D. Pathology. In: Brewis RAL, Gibson GJ, Geddes DM, eds. Respiratory Medicine. London: Baillière Tindall, 1990;16:3.

3 Eriksson S. Studies in alpha-1-antitrypsin deficiency. Acta Med Scand 1965;177 (suppl 432) $1-85$.

4 Snider GL. Emphysema: the first two centuries - and beyond. A historical overview, with suggestions for future research: part 2. Am Rev Respir Dis 1992;146:1615-22.

5 Fletcher C, Peto R. The natural history of chronic airflow obstruction. BMF 1977;i:1645-8.

6 Barker DJP, Godfrey KM, Fall C, Osmond C, Winter PD, Shaheen SO. Relation of birth weight and childhood respiratory infection to adult lung function and death from chronic obstructive lung disease. $B M^{\prime}$ 1 1991;303:671-5.

7 Samet JM, Tager IB, Speizer FE. The relationship between respiratory illness in childhood and chronic air-flow obstruction in adulthood. Am Rev Respir Dis 1983;127:508-23.

8 Bott J, Carroll MP, Conway JH, Keilty SEJ, Ward EM, Brown AM, et al. Randomised controlled trial of nasal ventilation in acute ventilatory failure due to chronic obstructive airways trolled trial of nasal ventilation in

9 Kaiser LR, Cooper JD, Trulock EP, Pasque MK, Triantafillou A, Haydock D, et al. The evolution of single lung transplantation for emphysema. $f$ Thorac Cardiovasc Surg 1991;102:333-9.

10 Hubbard RC, Sellars SE, Czerski D, Stephens L, Crystal RG. Biochemical efficacy and safety of monthly augmentation therapy for alpha-1-antitrypsin deficiency. $\mathscr{f} A M A 1988 ; 260$ : 1259-64.

11 Crystal RG. Gene therapy strategies for pulmonary disease. Am $f$ Med 1992;92 (suppl 6A):44-52S.

\title{
The failure of consultant expansion
}

\author{
The shortfall will cause many problems
}

An increase in the number of consultants, both absolutely and as a proportion of all hospital doctors, has been the central recommendation of every investigation into medical manpower and training since the early 1970s. Yet, the effect of all of these reports on consultant expansion over the past 25 years has been imperceptible. Despite repeated calls for a growth rate of $4 \%$ a year the actual rate has remained close to $2 \%$, almost exactly paralleling growth in the overall number of doctors working in the NHS. The latest figures from the health departments show no change or possibly a slight worsening, with an increase of only $1.9 \%$ in the number of consultants in 1992-3. In the same year the number of senior registrars increased by $4 \cdot 2 \%$ and senior house officers by $5 \%$. Appointments to the staff grade increased by $50 \%$.

Quite apart from the need to ensure a smooth progression of young doctors through postgraduate training, ensuring the efficient use of their skills, the demand for consultant labour is growing inexorably. The number of patients treated in NHS hospitals continues to increase. The patient's charter, numerous local additions to it, and the increasing technical complexity of new medical treatments all require that an ever greater proportion of care should be provided by consultants in person. Educational initiatives, and most recently the Calman report, ${ }^{1}$ require consultants to devote more of their time to training junior staff, and the demands made by audit and administration have also increased considerably. A survey in 1989 showed that consultants worked an average of 50 hours a week for the NHS, excluding on call commitments, ${ }^{2}$ just three hours less than the current average for junior doctors after partial implementation of the "new deal" on juniors' hours. Consultants' workload has certainly not fallen since then.

Sadly, there is no reason to expect that expansion in the number of consultants is about to accelerate. The wholesale abandonment of central planning in the NHS makes concerted action to change medical staff mix virtually impossible. NHS trusts, which must now meet the cost of consultants' salaries as well as the services that they provide, have a powerful disincentive to increase the number of consultants, given the parlous financial situation of many purchasers of health care and the resulting pressure to cut costs. Short term survival and solvency have become the compelling considerations rather than the longer term requirement for a well trained and efficiently managed medical workforce.

The medical profession and the government have nonetheless agreed to further far reaching reforms in specialist training that depend on substantial and rapid expansion of the number of consultants for their implementation. Hospital Doctors: Training for the Future (the Calman report) aims at bringing about a reduction in the duration of specialist training from its present average of 12 years to seven years. ${ }^{1}$ The report discusses restructuring the training grades but offers no solution to the intractable problem of achieving growth in the number of consultants.

Tinkering with the training grades will have no effect on the duration of training. The training grades are analogous to a reservoir whose water level (the duration of training) rises and falls depending on rates of inflow and outflow. 